\title{
Moluscos biválvios do Cretáceo Superior da Bacia de Sergipe: um estudo da seção turoniana Pedro Gonçalves
}

\author{
Upper Cretaceous bivalves of the Sergipe Basin: a study from the Turonian Pedro Gonçalves \\ Section
}

\author{
E. Franco Neto*; E. J. Andrade; M. N. Santana; H. F. S. Lima \\ Departamento de Geologia, Universidade Federal de Sergipe, Campus Professor José Aloísio de Campos, 49100-000, \\ Aracaju, Sergipe, Brasil
}

*emmanuel_franco_neto@outlook.com

(Recebido em 14 deagosto de 2019; aceito em 10 de setembro de 2019)

\begin{abstract}
A Bacia de Sergipe apresenta uma sucessão estratigráfica completa e rica fauna fóssil. No intervalo Cenomaniano Superior, um grande evento transgressivo proporcionou a instalação da Formação Cotinguiba (Cretáceo Superior), caracterizada pela deposição de um conjunto de rochas carbonáticas com gênese associada à um ambiente deposicional de rampa. Litologicamente, calcilutitos e margas proximais representam o Membro Sapucari, enquanto folhelhos distais marcam o Membro Aracaju, nestas rochas os moluscos biválvios são abundantes. Este trabalho tem como principal objetivo identificar e descrever sistematicamente os moluscos da classe Bivalvia da seção Pedro Gonçalves, Formação Cotinguiba, Cretáceo Superior de Sergipe. A área de estudo está localizada entre os municípios de Rosário do Catete e General Maynard, Sergipe. O material de estudo é constituído de 238 exemplares de moluscos biválvios provenientes da localidade Pedro Gonçalves. Foram identificados 27 táxons, distribuídos em 19 gêneros e 14 famílias: Cucullaeidae, Pinnidae, Inoceramidae, Plicatulidae, Pectinidae, Ostreidae, Gryphaeidae, Cardiidae, Dicerocardiidae, Corbulidae, Pholadomyidae, Pleuromyidae e Poromyidae. A seção é posicionada no intervalo Turoniano médio baseada na fauna de biválvios inoceramídeos.
\end{abstract}

Palavras-chave: Paleontologia, Sistemática, Formação Cot in guiba.

The Sergipe Basin has a full stratigraphic record and abundant fossil fauna. At the upper Cenomanian interval, a great transgressive event allowed the deposition of Cotinguiba Formation (Upper Cretaceous). The formation is characterized by the deposition of carbonatic rocks in association with a geometric model of ramp as deposicional environment. Litologically, mudstone and marls show up at the Sapucari Member and changes to distal shale at the Aracaju Member. These rocks present a very representative fauna of bivalves. This study aims to describe and identify of the Class Bivalvia of the Pedro Gonçalves section, Cotinguiba Formation. The material studied was collected at the Pedro Gonçalves locality, situated between the cities Rosário do Catete and General Maynard (Sergipe state). It comprises 238 specimens of bivalves. Twenty seven taxons were identified, among these 19 genera and 14 families: Cucullaeidae, Pinnidae, Inoceramidae, Plicatulidae, Pectinidae, Pectinidae, Ostreidae, Gryphaeidae, Cardiidae, Dicerocardiidae, Corbulidae, Pholadomyidae, Pleuromyidae e Poromyidae. Based on the inoceramids bivalves fauna this section is dated from the middle Turonian.

Keywords: Paleontology, Systematic, Cotinguiba Formation.

\section{INTRODUÇÃO}

A sucessão estratigráfica da Bacia de Sergipe apresenta uma das associações fossilíferas mais ricas dentre as bacias sedimentares da margem continental brasileira. Destaca-se a presença dos bivalves, amonoides, gastrópodes e equinoides. Essa macrofauna é, principalmente, encontrada nas rochas das formações Riachuelo e Cotinguiba, que sinalizam o início da fase de sedimentação marinha durante o Cretáceo [1].

O intervalo Turoniano (Cretáceo Superior) é bem representado na sucessão marinha da Formação Cotinguiba. Neste intervalo, os moluscos biválvios apresentam abundância fossilífera. 
Esse grupo foi objeto de diversos trabalhos relacionados à paleontologia, paleoecologia, bioestratigrafia e estudos paleoambientais desenvolvidos a partir de meados do século XIX $[1,2]$. Trabalhos taxonômicos foram realizados por diversos autores [3 - 17].

As famílias Inoceramidae, Ostreidae, Limidae, Pectinidae, Cardiidae, Pholadomyidae e Pleuromyidae são as principais representantes da fauna bentônica encontrada nos depósitos carbonáticos da Formação Cotinguiba. Os inoceramídeos, junto aos amonoides, são utilizados como base para o zoneamento bioestratigráfico do intervalo Turoniano. Apesar da abundância, a sistemática desse grupo é complexa, sobretudo, em razão do estado de preservação do material encontrado, principalmente pela perda de características morfológicas, através da dissolução das conchas. Como consequência, características importantes para a identificação específica, como estruturas internas e externas, são perdidas.

A Formação Cotinguiba (Cenomaniano-Coniaciano) apresenta diversos afloramentos que possibilitam a coleta e o estudo de macrofauna de moluscos. A identificação e descrição sistemática dos biválvios contribuirá para a evolução do conhecimento paleontológico desta formação. Este trabalho tem como principal objetivo identificar e descrever sistematicamente os moluscos da classe Bivalvia da seção Pedro Gonçalves, Formação Cotinguiba, Cretáceo Superior de Sergipe.

\subsection{Arcabouço Geológico}

A Bacia de Sergipe é uma das bacias da margem continental brasileira localizada na região nordeste, entre os paralelos $9^{\circ}$ e $10^{\circ}$, dentro dos estados que lhe conferem nome (Figura 1). No final Jurássico e início do Cretáceo, o rifteamento do supercontinente Gondwana promoveu o desenvolvimento de diversas bacias rifte na margem continental brasileira. Neste contexto de formação, a Bacia de Sergipe apresenta a coluna estratigráfica mais completa em termos de registros estratigráficos da evolução de uma bacia rifte [18, 19].

A sucessão estratigráfica Bacia de Sergipe-Alagoas está subdividida em quatro supersequências deposicionais: pré-rifte, rifte, pós-rifte e drifte. Estas sequências repousam sobre o embasamento metamórfico da Faixa de Dobramentos Sergipana e do maciço Pernambuco-Alagoas [19].

Um evento transgressivo iniciado no Cenomaniano causou o afogamento da plataforma rasa da Formação Riachuelo, onde foram depositados os sedimentos da Formação Cotinguiba em um ambiente de rampa carbonática. Esse evento se estendeu até o Coniaciano, onde uma discordância marca o contato entre as formações Cotinguiba e Calumbi [19, 20, 21].

A Formação Cotinguiba desenvolveu-se em um ambiente deposicional de talude profundo, entre os intervalos Cenomaniano e Coniaciano (Figura 2). Dois membros foram individualizados nessa sucessão: Sapucari e Aracaju. Calcilutitos e margas proximais representam o Membro Sapucari, enquanto folhelhos distais marcam o Membro Aracaju [19]. As regiões mais espessas da formação foram associadas às áreas de maior índice de subsidência térmica [20].
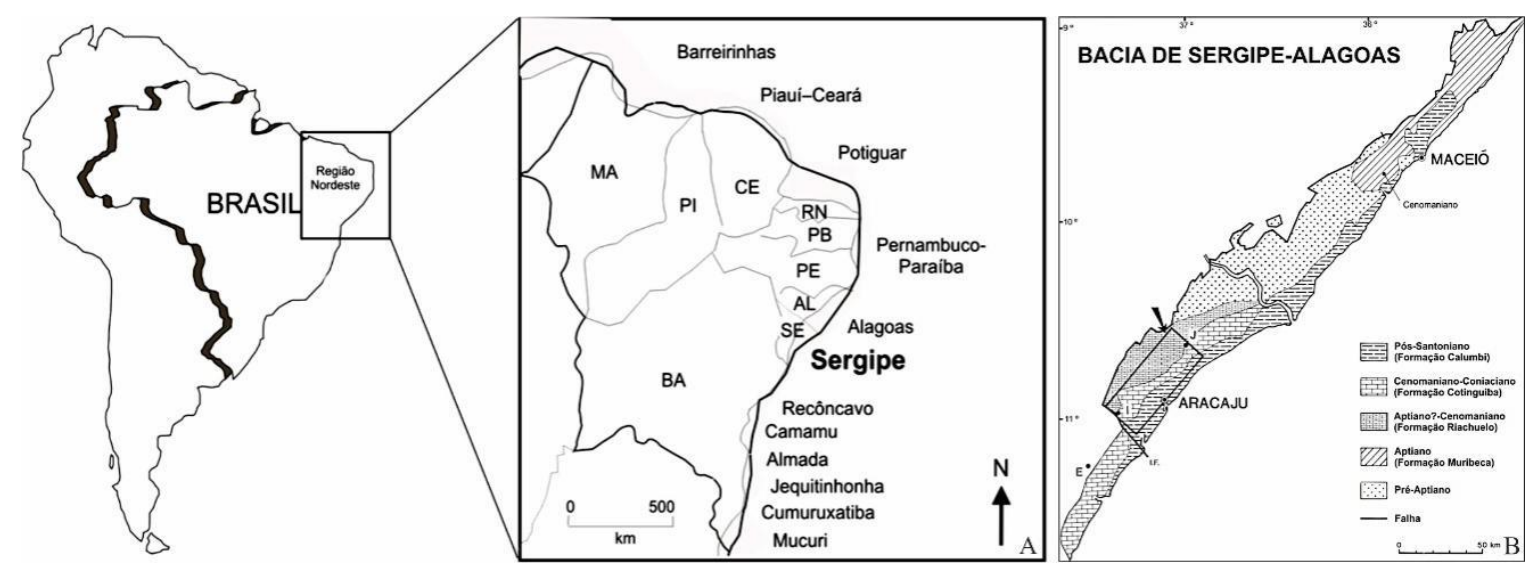

Figura 1: A Localização das bacias sedimentares marginais do nordeste do Brasil. Em destaque a Bacia de Sergipe. Abreviatura dos nomes dos estados: AL Alagoas, BA Bahia, CE Cea rá, MA Maranhão, PB 
Paraíba, PE Pernambuco, PI Piauí, RN Rio Grande do Norte, SE Sergipe. Modificado de Bengtson (1983) [1] e Andrade (2005) [12]. B Localização da porção onshore da Bacia de Sergipe-Alagoas. Fonte: Modificado de Bengtson (1983) [1]

\begin{tabular}{|c|c|c|c|c|}
\hline Idade & Fm. & Membro & Litologia & Ambiente \\
\hline Coniaciano & \multirow{3}{*}{ 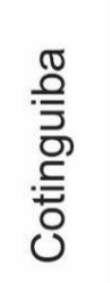 } & \multirow{2}{*}{ Sapucari } & & \multirow{2}{*}{ Talude } \\
\hline Turoniano & & & & \\
\hline Cenomaniano & & Aracaju & & Profundo \\
\hline Albiano & \multirow{2}{*}{$\begin{array}{l}\frac{0}{0} \\
\frac{1}{2} \\
\frac{1}{0} \\
\frac{\pi}{\square}\end{array}$} & \multirow{2}{*}{$\begin{array}{l}\text { Maruim } \\
\text { Taquari } \\
\text { Angico }\end{array}$} & & \multirow{2}{*}{$\begin{array}{l}\text { Leques } \\
\text { aluvio- } \\
\text { deltaicos/ } \\
\text { Plataforma/ } \\
\text { Talude }\end{array}$} \\
\hline Aptiano & & & & \\
\hline
\end{tabular}

Figura 2: Esboço estratigráfico da sequência marinha cretácica das formações Riachuelo e Cotinguiba, Bacia de Sergipe. Fonte: Modificado de Souza-Lima (2002) [18] e Campos Neto et al. (2007) [19].

\section{MATERIAL E MÉTODOS}

\subsection{Localização da área de estudo}

Este trabalho abrange a localidade Pedro Gonçalves 6 (Figura 3), situada entre os municípios de Rosário do Catete e General Maynard, Microrregião do Baixo Cotinguiba (leste do estado de Sergipe). A seção de estudo compreende uma pedreira ativa particular de exploração de calcário com face de lavra voltada para NE, com atitude principal N 84/14 ${ }^{\circ}$. Possui aproximadamente 100 $\mathrm{m}$ de largura com $20 \mathrm{~m}$ de altura na parede mais alta.

A seção Pedro Gonçalves 6 (PG06) está inserida na Folha Japaratuba (SC.24-Z-B-V) e possui as seguintes coordenadas UTM (zona 24S): $8.816 .187 \mathrm{~N}$ e $720.895 \mathrm{E}$. As coordenadas foram retiradas sobre o Datum SIRGAS 2000. Outras cinco localidades (PG01-PG05) próximas a área de estudo foram descritas por Bengtson (1983) [1] e algumas delas poderão ser incorporadas com o avanço da lavra (Figura 3).

Em termos litológicos, a seção PedroGonçalves 6 é constituída pela intercalação de calcilutitos e margas, localmente bioturbados. Brechas carbonáticas e bancos de ostreídeos podem ser observados esparsamente em direção ao topo da seção. 

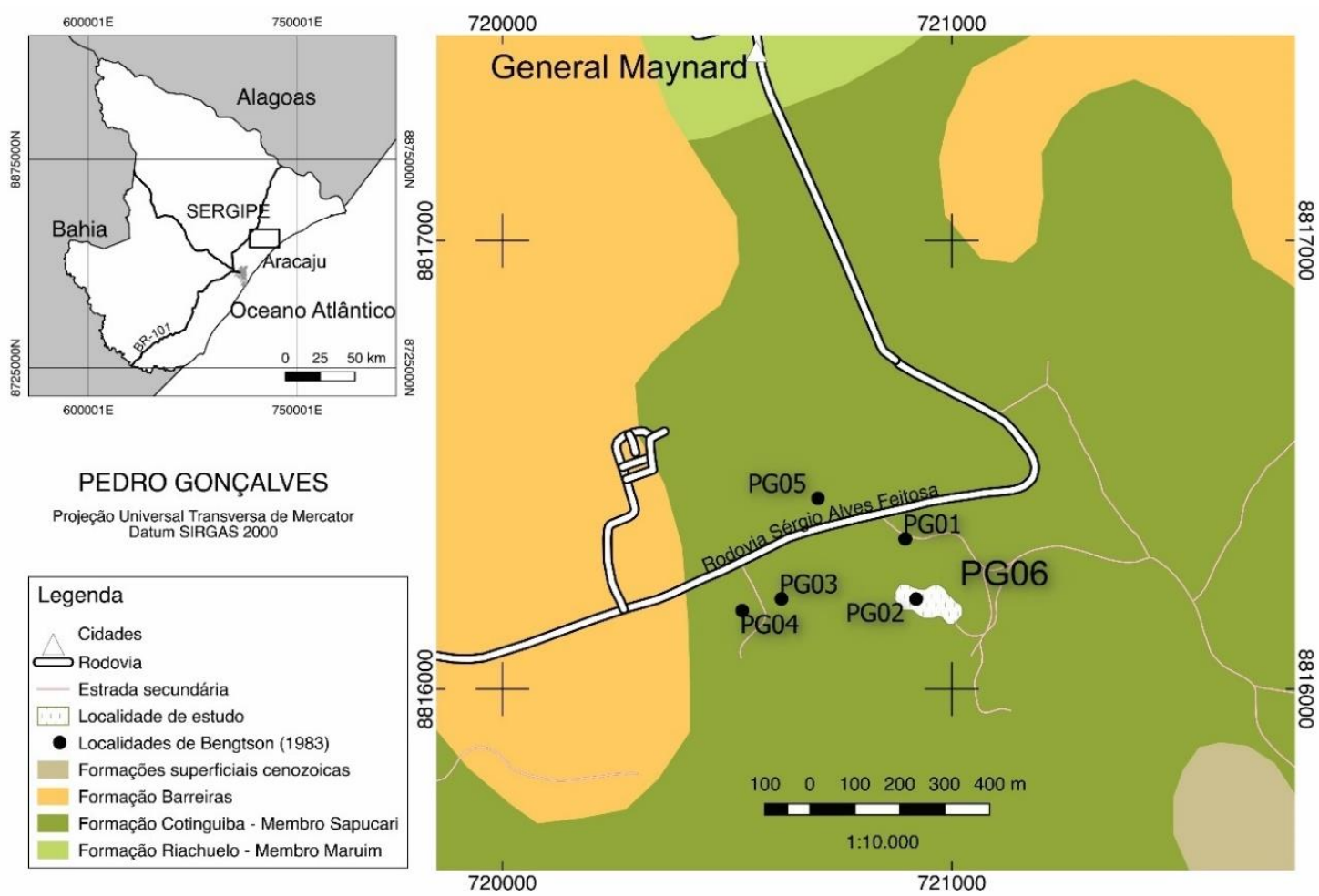

Figura 3: Localização da área de estudo em Sergipe, em destaque a localidade Pedro Gonçalves 6 (PG06).

\subsection{Preparação dos exemplares de biválvios}

O desenvolvimento desse trabalho foi baseado no estudo de moluscos fósseis da classe Bivalvia coletados na seção Pedro Gonçalves 6 (PG06). Foram coletados e preparados 238 exemplares de biválvios. Após a preparação, os melhores exemplares foram numerados e medidos com auxílio de um paquímetro, com resolução de $0,05 \mathrm{~mm}$. Em seguida foram fotografados, identificados e descritos sistematicamente. A sistemática segue as indicações de Cox et al. (1969) [22] até o nível genérico.

Os fósseis estão depositados no Laboratório de Mineralogia e Paleontologia do Departamento de Geologia da Universidade Federal de Sergipe (UFS).

\section{Terminologia}

As abreviaturas apresentadas em seguida referem-se as medidas e características morfológicas dos biválvios (Figura 4). As medidas realizadas estão em milímetro ( $\mathrm{mm}$ ).

$\mathrm{L}=$ Largura;

A = Altura;

$\mathrm{C}=$ Convexidade das valvas articuladas;

* = Medida incompleta devido ao estado de preservação do exemplar;

- = Medida não realizada. 

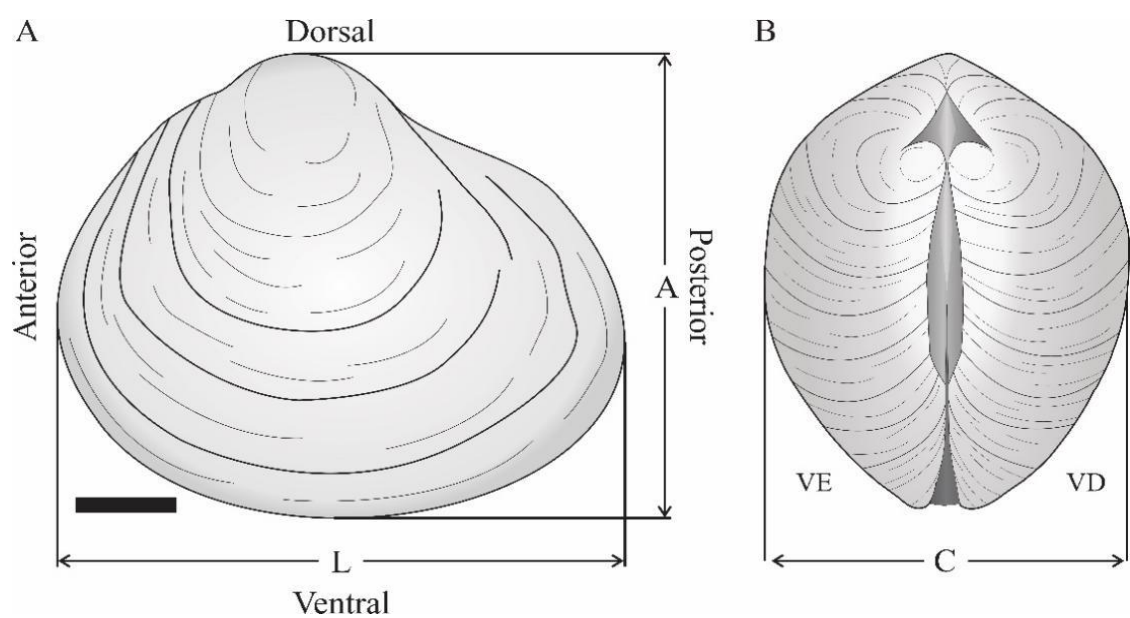

Figura 4: Características morfológicas e medidas dos biválvios. A. vista lateral da valva esquerda e B. vista dorsal. Escala $=10 \mathrm{~mm}$. Fonte: Os autores

\section{RESULTADOS E DISCUSSÃO}

\section{Sis temática pale ontológica}

Filo Mollusca Linnaeus, 1758

Classe Bivalvia Linnaeus, 1758

Subclasse Pteriomorphia Beurlen, 1944

Ordem Arcoida Stoliczka, 1871

Superfamília Arcacea Lamarck, 1809

Familia Cucullaeidae Stewart, 1930

Gênero Cucullaea Lamarck, 1801

Subgênero Idonearca Conrad, 1862

\section{Cucullaea (Idonearca) sp.}

(Figura 5: A)

Mate rial. Um exemplar preservado como molde interno (PG06-381).

Descrição. Valva moderadamente inflada, inequilateral e de tamanho médio. Altura da concha igual a $26 \mathrm{~mm}$ e largura a $25 \mathrm{~mm}$. Margem anterior curta e arredondada. Margem posterior reta e unida com a margem ventral em ângulo quase reto. Margem ventral ligeiramente arredondada. Umbo subtriangular e estreito. Marca do músculo anterior preservada. Ornamentação não preservada.

Discussão. O material descrito se assemelha no formato da concha ao exemplar de Cucullaea (Idonearca) thevestensis (Coquand, 1862) descrito e ilustrado (estampa 2, Figura 2) para o intervalo Cenomaniano-Turoniano (Cretáceo Superior) da Península de Sinai [23]. Entretanto, o exemplar da Formação Cotinguiba possui o umbo mais estreito, além da falta de ornamentação que impossibilitou a designação específica.

Ocorrência. Turoniano de Sergipe, Brasil (nesse estudo).

Ordem Mytiloida Férussac, 1822

Subordem Malleidina J. Gray, 1854

Superfamília Pinnacea Leach, 1819

Família Pinnidae Leach, 1819

Gênero Pinna Linnaeus, 1758

Pinna sp.

(Figura 5: B-C) 
Mate rial. Dois exemplares incompletos preservados como molde interno (PG06-87 e PG06-102). Descrição. Concha alongada, subtriangular, moderadamente inflada, inequilateral e de tamanho médio, com altura média de $30,5 \mathrm{~mm}$ e a largura de $53,5 \mathrm{~mm}$. Margem ventral reta a ligeiramente convexa e dorsal reta a ligeiramente côncava.

Discussão. Pinídeos são membros da macrofauna bentônica que se destacam no registro fóssil devido à forma peculiar das conchas e ao hábito de vida seminfaunal. O gênero é particularmente abundante em Sergipe no intervalo entre o Turoniano superior e o Coniaciano inferior [15]. Seeling e Bengtson (2003) [9] discutiram a sistemática, paleobiogeografia e a paleoecologia de Pinna cretacea proveniente da Fm. Cotinguiba. Bengtson et al. (2014) [15] reavaliaram o material estudado por Seeling e Bengtson (2003) [9] e descreveram as subespécies Pinna cretaceacretacea e Pinna cretacea brevis com base nas diferenças de contorno e ângulo apical das valvas. As características morfológicas dos exemplares analisados (e.g. forma e margens das conchas) assemelham-se ao gênero Pinna. O tamanho dos exemplares indica que o material descrito provavelmente corresponde a um estágio ontogenético juvenil. Ademais, a preservação do material impede uma identificação específica.

Ocorrência. Turoniano de Sergipe, Brasil (nesse estudo).

Ordem Pterioida Newell, 1965

Subordem Pterïna Newell, 1965

Superfamília Pteriaceae Gray, 1847

Família Inoceramidae Giebel, 1852

Gênero Mytiloides Brongniart, 1822

Mytiloides subhercynicus (Seitz, 1935)

(Figura 5: D-E)

pars 1935 Inoceramus labiatus n. var. subhercynica - Seitz, p. 465, est. 40, fig. 1 (non est. 40, figs 2 e 5; text-figs 18a- $\mathrm{f}=$ M. goppelnensis).

2000 Mytiloides subhercynicus (Seitz, 1935) - Walaszczyk \& Cobban, p. 327-329, est. 15, figs 17.

2005 Mytiloides subhercynicus (Seitz, 1935) - Andrade, p. 71, est. 4, figs. 7-10. (com lista de sinonímia).

Material. Três exemplares incompletos preservados como molde interno, com resto de concha (PG06-166, PG06-168 e PG06-173).

Descrição. Concha de tamanho médio, pouco inflada, inequilateral, contorno obliquamente alongado a suboval. O umbo não está preservado. A margem anterior é arredondada e a posterior quase reta. A ornamentação composta de rugas ligeiramente assimétric as cobertas por finas linhas de crescimento.

Discussão. Os exemplares analisados apresentam formato e ornamentação da concha semelhantes aos exemplares de Mytiloides subhercynicus descrito para a localidade Retiro 26, da Formação Cotinguiba [12]. Os espécimes exibem a separação bem marcada entre a auríc ula posterior e o disco central na parte juvenil, bem como o eixo de crescimento alongado no sentido posteroventral (espécimes PG06-166, fig. 5E, e PG06-173, fig. 5D, respectivamente), características distintas da espécie, como destacado por Walaszczyk e Coban (2000) [24] e Andrade (2005) [12].

Ocorrência. Turoniano médio da República Tcheca, Inglaterra, França, Alemanha, Polônia, Espanha, Tunísia, Colômbia, Estados Unidos (US Western Interior) e Sergipe, Brasil [12, 24]. 
Mytiloides hercynicus (Petrascheck, 1903)

1903 Mytiloides hercynicus n. sp. - Petrascheck, p. 156-158, est. 8 figs 1-3, text-fig. 1. 1992 Mytiloides hercynicus (Petrascheck, 1903) - Walaszczyk, p. 17-19, est. 5, figs 1-5. 2005 Mytiloides hercynicus (Petrascheck, 1903) - Andrade, p. 73, est. 5, figs. 1-4, 7-10 (com lista de sinonímia).

Mate rial. Dois exemplares incompletos preservados como molde interno, com resto de concha (PG06-167 e PG06-169).

Des crição. Concha pequena e contorno arredondado. Margens anterior e posterior arredondadas. Umbo não preservado. A ornamentação é composta por rugas concêntricas, estreitas e espaçadas, cobertas por linhas de crescimento.

Discussão. O material analisado se assemelha aos exemplares de Mytiloides hercynicus descrito para a seção Retiro 26 (Cretáceo Superior) da Bacia de Sergipe [12]. Os dois exemplares aqui estudados estão preservados em estágio ontogenético juvenil. Walaszczyk e Coban (2000) [24] e Andrade (2005) [12] salientam a escassez de estudos sobre as diferenças entre M. subhercynicus e $M$. hercynicus. Ambos táxons exibem a quebra proeminente entre a aurícula e o disco, porém diferem na obliquidade da concha e mudança na ornamentação da fase juvenil e adulta.

Ocorrência. Turoniano médio do República Tcheca, França, Alemanha, Polônia, Portugal, Espanha, possivelmente Marrocos e norte do Cáucaso,Estados Unidos (Western Interior), México e Sergipe, Brasil [12].

\section{Mytiloides spp.}

(Figura 5: F)

Material. Três exemplares incompletos preservados como molde interno e restos da concha (PG06-170-PG06-172).

Des crição. Concha inequilateral e com o contorno oval a subarredondado. Umbo pouco proeminente e linha de charneira reta. Margem anterior arredondada e posterior fragmentada. A ornamentação é composta por rugas arredondadas e assimétricas.

Discussão. Os exemplares apresentam diferenças no contorno e ornamentação das valvas que sugerem mais de uma espécie. Porém, o estado de preservação dos moldes incompletos não permite uma diferenciação específica.

Ocorrência. Turoniano de Sergipe, Brasil (nesse estudo).

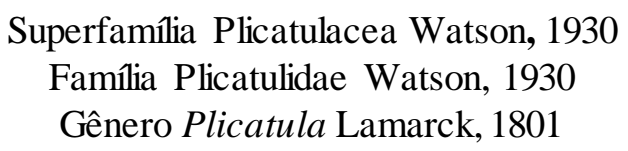

Plicatula sp.

(Figura 5: G)

Mate rial. 30 exemplares preservados como concha, molde interno ou externo (PG06-140, PG06141, PG06-143-PG06-146, PG06-148, PG06-150-PG06-152, PG06-157, PG06-228, PG06-253, PG06-281-PG06-291, PG06-297, PG06-393-PG06-397).

Descrição. Concha pequena, subtriangular, equilateral, moderadamente inflada e com a altura maior que a largura (média da relação largura e altura igual a 0,85). A altura e largura média das conchas é igual a $29,8 \mathrm{~mm}$ e $25,3 \mathrm{~mm}$ respectivamente (Tabela 1). Umbo pequeno e pouco proeminente. Margem anterior convexa e posterior côncava. Ornamentação composta por cerca de 20 costelas radiais rugosas separadas por espaços largos. 
Tabela 1: Medidas dos exemplares selecionados de Plicatula sp.

\begin{tabular}{llll}
\hline Exemplar & L & A & L/A \\
\hline PG06-146 & 32 & 35 & 0,91 \\
PG06-148 & 21 & 23 & 0,91 \\
PG06-151 & 23 & 25 & 0,92 \\
PG06-152 & 29 & 33 & 0,87 \\
PG06-228 & 28 & 37 & 0,76 \\
PG06-394 & 24 & 33 & 0,73 \\
PG06-396 & 20 & 23 & 0,87 \\
\hline
\end{tabular}

Discussão. Os exemplares de Plicatula sp. se assemelham à Plicatula ferryi Coquand (1862), descrita para Formação Matulla [25] e para a Península de Sinai [26], ambos do CretáceoSuperior do Egito. O material egípcio apresenta ornamentação, forma e convexidade da concha semelhantes aos exemplares aqui analisados. O material de Sergipe é majoritariamente composto por moldes. Os exemplares que preservam concha estão fragmentados e ligeiramente desgastados, com a ornamentação pouco preservada, o que dificultou a análise do número de costelas. Assim, optou-se por deixar em nomenclatura aberta.

Ocorrência. Turoniano de Sergipe, Brasil (nesse estudo).

Superfamilia Pectinacea Rafinesque, 1815

Familia Pectinidae Rafinesque, 1815

Gênero Camptonectes Agassiz in MEEK, 1864

\section{Camptonectes sp.}

(Figura 5: H)

Mate rial. Um molde interno incompleto com resto de concha (PG06-16).

Des crição. Concha de tamanho médio, subtriangular e quase plana, com a altura igual a $44 \mathrm{~mm}$ e a largura a $39 \mathrm{~mm}$. Margem posterior arredondada e anterior um pouco mais reta. Umbo estreito. Ornamentação marcada por costelas radiais finas parcialmente preservadas.

Discussão. O exemplar analisado é semelhante à Camptonectes platessa (White, 1874) descrita para as formações Dakota e Toreva [27], Cretáceo Superior da Bacia Black Mesa, no formato e na margem da concha, porém o estado de preservação da ornamentação impede a identificação específica.

Ocorrência. Turoniano de Sergipe, Brasil (nesse estudo).

Superfamília Limacea Rafinesque, 1815

Família Limidae Rafinesque, 1815

Gênero Plagiostoma J. Sowerby, 1814

Plagiostoma sp.

(Figura 5: I)

Mate rial. Dois exemplares preservados como molde interno e contramolde da concha (PG06-15 e PG06-264).

Des crição. Valva grande, moderadamente inflada, suboval a subtriangular, com a média da altura igual 69,5 mm e média da largura igual $77 \mathrm{~mm}$. Margem posterior e anterior levemente retas. Margem ventral arredondada. Umbo proeminente. Ornamentação caracterizada por linhas de crescimento concêntricas ligeiramente desgastadas.

Discussão. Plagiostoma sp. é semelhante no contorno da concha à Plagiostoma hoperi (Mantell, 1822) descrita e ilustrada para o Campaniano Inferior da Suécia [28]. Entretanto, no material da Suécia a ornamentação também é composta de linhas de crescimento radiais. Da mesma maneira, 
os exemplares analisados são semelhantes à Plagiostoma cretaceum (Woods, 1904), ilustrada para a Formação Hochmoos [29], Cretáceo Inferior da Áustria. Porém, os exemplares de Sergipe apresentam concha com altura e a largura maiores e linhas de crescimento mais finas que aquelas observadas em $P$. cretaceum. Devido ao estado de preservação dos exemplares estudados não foi possível a identificação específica.

Ocorrência. Turoniano de Sergipe, Brasil (nesse estudo).

Gênero Pseudolimea Arkell, 1932

\section{Pseudolimea $\mathrm{sp}$.}

(Figura 5: J)

Material. Cinco exemplares preservados como molde interno e externo (PG06-48, PG06-125, PG06-192, PG06-292 e PG06-298).

Descrição. Concha pequena, subtrigonal a oval, convexa e equilateral, com altura média equivalente a $19 \mathrm{~mm}$ e largura a $17 \mathrm{~mm}$. Umbo proeminente. As margens anterior e posterior são retas. Ornamentação composta por costelas radiais separadas por espaços regulares.

Discussão. Pseudolimea sp. é semelhante aos exemplares de Limea (Pseudolimea) denticulata (Nilsson, 1827), do CretáceoInferior da Europa [30], em relaçãoà ornamentação. Porém diferemse na maior convexidade da concha no material de Sergipe. Os exemplares analisados são similares à Pseudolimea itieriana (Pictet \& Roux, 1852), ilustrada para o intervalo CenomanianoTuroniano inferior do Egito [31], em relação à ornamentação e forma da concha, e diferem na maior convexidade dos exemplares da Formação Cotinguiba.

Ocorrência. Turoniano de Sergipe, Brasil (nesse estudo).

Superfamília Ostreoidea Rafinesque, 1815

Família Ostreidae Rafinesque, 1815

Gênero Crassostrea Sacco, 1897

Crassostreasp.

(Figura 5: K-M)

Material. 83 exemplares incompletos preservados como concha. Na maioria dos casos estão presentes as valvas esquerdas, com algumas ainda articuladas (PG06-65-PG06-84, PG06-88PG06-101， PG06-103-PG06-106， PG06-110， PG06-114-PG06-123， PG06-126-PG06-129, PG06-179, PG06-191， PG06-273-PG06-275， PG06-293-PG06-296， PG06-307-PG06-319, PG06-324, PG06-340, PG06-341, PG06-357, PG06-368-PG06-370 e PG06-398).

Des crição. Concha comforma alongada a irregular, altura média igual a 63,3 mm e largura média a 45,8 mm (Tabela 2). Contorno irregular, geralmente reto ou pouco arredondado. Valva esquerda com umbo proeminente acima da linha de charneira e margem ventral convexa, semelhante a uma dobra central. Valva direita quase plana. Ornamentação composta por suaves linhas de crescimento lamelares e rugas irregulares.

Tabela 2: Medidas dos exemplares selecionados de Crassostrea sp.

\begin{tabular}{cccc}
\hline Exemplar & L & A & L/A \\
\hline PG06-65 & 38 & 45 & 0,84 \\
PG06-71 & 41 & 49 & 0,83 \\
PG06-116 & 58 & 82 & 0,70 \\
PG06-117 & 59 & 100 & 0,59 \\
PG06-128 & 50 & 74 & 0,67 \\
PG06-398 & 29 & 30 & 0,97 \\
\hline
\end{tabular}


Discussão. Os exemplares completos apresentam variações na relação largura/altura de acordo com o estágio ontogenético. Conchas juvenis exibem os maiores valores (média de 0,88), enquanto nos adultos a relação média chega a 0,65 .

O material descrito é semelhante aos exemplares de Crassostrea subtriangularis (Evans \& Shumard, 1857), descritos para o Cretáceo Superior da Polônia, em termos de ornamentação [32]. Entretanto, C. subtriangularis apresenta valva mais convexa, dobra central na região ventral e maior largura e altura das valvas.

Crassostrea sp. possui a ornamentação semelhante aos exemplares de Crassostrea soleniscus (Meek, 1871) descritos e ilustrados para o Cretáceo Superior da Bacia Black Mesa [27]. Porém, os exemplares da Formação Cotinguiba possuem a margem ventral convexa e a concha menos alongada do que a de C. soleniscus.

Os exemplares analisados são semelhantes à Ilymatogyra (Afrogyra) africana (Lamarck, 1801) descrita e ilustrada para a Bacia Costeira do Gabão no formato da concha [33]. Entretanto, I. (A.) africana difere pela presença de lamelas de crescimento escamosas bem desenvolvidas e valva direita ligeiramente mais convexa. A maioria dos exemplares analisados estão incompletos e com a ornamentação desgastada. Por isso, não foi possível a identificação específica.

Ocorrência. Turoniano de Sergipe, Brasil (nesse estudo).

Família Gryphaeidae Vialov, 1936

Subfamília Pycnodonteinae Stenzel, 1959

Gênero Pycnodonte Fischer de Waldheim, 1835

Pycnodonte sp.

(Figura 5: N)

Mate rial. Um exemplar incompleto com concha (PG06-197).

Des crição. Concha pequena, suboval e bastante convexa. A altura desse exemplar é igual a 15 $\mathrm{mm}$ e largura a $16 \mathrm{~mm}$. Apresenta sulcos bem desenvolvidos na região posterior. Umbo e resilífero não preservados. Ornamentação composta por finas linhas de crescimento.

Discussão. Pycnodonte sp. ornamentação semelhante aos exemplares de Pycnodonte (Phygraea) bechkochensis (Weber, 1934) descrito para o Cretáceo Superior da Polônia [32]. Entretanto, a concha de $P$. $(P$.) bechkochensis apresenta maior altura, largura e convexidade do que o material da seção estudada.

O exemplar analisado é similar à Pycnodonte (Phygraea) vesiculosa (J. Sowerby, 1823) descrito para o Cretáceo Superior de Sergipe [8], na forma da concha, porém Pycnodonte sp. tem linhas de crescimento ligeiramente mais grossas.

Ocorrência. Turoniano de Sergipe, Brasil (nesse estudo).

Subclasse Heterodonta Neumayer, 1883

Ordem Veneroida Adams \& A. Adams, 1856

Superfamília Cardiacea Lamarck, 1809

Família Cardiidae Lamarck, 1809

Subfamília Cardiinae Lamarck, 1809

Gênero Granocardium Gabb, 1869

Subgênero Granocardium Gabb, 1869

Granocardium (Granocardium) productum (J. de C. Sowerby, 1832)

(Figura 5: O-P)

1832 Cardium productum - J. Sowerby in Sedgwick \& Murchison, p. 347, est. 39, fig. 15. 
1912 Cardium (Trachycardium) productum J. de C. Sowerby - Pervinquière, p. 259, est. 19, fig. 25.

1987 Granocardium productum (J. Sowerby, 1832) - Dhondt, p. 77, est. 4, figs 5-6.

1994 Granocardium cf. productum (J. de C. Sowerby, 1832) - Malchus et al., p. 133, est. 4, fig. 1.

2002 Granocardium productum (Sowerby, 1832) - Abdelhamid \& El Qot, p. 277, est. 5, figs. 78.

2006 Granocardium productum (J. de C. Sowerby, 1832) - El Qot, p. 77, est. 16, figs. $2 b, 3$.

2012 Granocardium productum(J. DE C. SOWERBY, 1832) - Benyoucef et al., est. 3, fig. 8.

2013 Granocardium productum (J. De C. Sowerby, 1832) - El Qot et al., p. 218, est. 5, fig. 4.

2013 Granocardium productum (J. Sowerby) - Musavu Moussavou et al., p. 4, fig. 3/10-14.

2014 Granocardium (Granocardium) productum (J. de C. Sowerby 1832) - Ayoub-Hannaa et al., p. 114, est. 10, figs 5-6.

2014 Granocardium productum (J. De C. Sowerby, 1832) - Hewaidy et al., p. 225, est. 2, fig. 8ab.

2015 Granocardium productum (J. de C. Sowerby) - Nagm, p. 15, fig. 6J.

2018 Granocardium (Granocardium) productum (J. DE C. SOWERBY, 1832) - Aouissi et al., p. 19, fig. 5.11 .

2019 Granocardium productum (J. de C. Sowerby, 1832) - Ghenim et al., p. 29, figs. 5 E1-2, 6

A1-3.

2019 Granocardium (Granocardium) productum(J. de C. Sowerby, 1832) - Ayoub-Hannaa et al., p. 180, est. V, figs. H-L. (com lista de sinonímia).

Mate rial. Quatro exemplares preservados como molde interno (PG06-49, PG06-376, PG06-377 e PG06-382).

Descrição. Concha de tamanho médio, inflada, subquadrangular, com altura média de $49 \mathrm{~mm}$ e largura média de $35,7 \mathrm{~mm}$ (Tabela 3). Margem anterior e posterior truncadas. Umbo proeminente e ligeiramente curvado. Ornamentação caracterizada por costelas radiais finas.

Tabela 3: Medidas dos exemplares selecionados de Granocardium (Granocardium) productum(J. de C. Sowerby, 1832).

\begin{tabular}{cccc}
\hline Exemplar & L & A & L/A \\
\hline PG06-49 & 35 & 38 & 0,92 \\
PG06-376 & $40^{*}$ & 58 & $0,69^{*}$ \\
PG06-377 & $32^{*}$ & 51 & $0,63^{*}$ \\
\hline
\end{tabular}

Discussão. Granocardium (Granocardium) productum apresenta algumas características morfológicas (e.g. dimensão e convexidade da concha) similares à Protocardia (Pachycardium) pauli (Coquand, 1862). Entretanto, ornamentação, formato do umbo e da concha diferem nessas espécies.

Os exemplares analisados se assemelham à G. productum descrito para o Cretáceo Superior do Egito na forma, convexidade e ornamentação da concha $[23,26]$. O material de Sergipe é semelhante ao descrito e ilustrado para o Cenomaniano do Nordeste [34] e Sudeste [35] da Argélia. Ocorrência. Aptiano-Turoniano da Índia; Cenomaniano da Portugal e da Argélia; CenomanianoSantoniano do Egito; Cenomaniano-“Senoniano" dos Camarões, Congo, Angola e Gabão; Turoniano da Jordânia, Tunísia e Nigéria; Coniaciano-Campaniano Inferior da Italia; Santoniano da Áustria; Campaniano da Alemanha, França e noroeste da Europa; Maastrichtiano da Polônia; Santoniano da Bélgica; Cenomaniano-Turoniano de Sergipe, Brasil [17, 29, 34, 35, 36, 37, 38]. 


\section{Granocardium sp.}

(Figura 5: S)

Mate rial. Um exemplar preservado como molde externo com restos da concha (PG06-254).

Descrição. Concha subquadrangular, moderadamente inflada e grande, com a largura igual a 31 $\mathrm{mm}$ e altura a $43 \mathrm{~mm}$. Margem anterior convexa, margem posterior ligeiramente côncava. Umbo não preservado. Ornamentação composta por costelas radiais preenchidas por pequenos espinhos ao longo da concha.

Discussão. O exemplar analisado apresenta a ornamentação preservada, entretanto, a concha está bastante fragmentada. Por isso, optou-se em deixar a espécie em nomenclatura aberta.

Granocardium sp. difere de Granocardium productum por ter a concha mais convexa e ornamentação marcada pela presença de costelas radiais largas e pequenos espinhos.

O material da Formação Cotinguiba é semelhante à Granocardium (Granocardium) desvauxi (Coquand, 1862), descrito e ilustrado para o Cenomaniano da Argélia [35], em relação à ornamentação. Entretanto, difere-se pela presença de costelas radiais mais grossas no exemplar de Sergipe.

Ocorrência. Turoniano de Sergipe, Brasil (nesse estudo).

Subfamília Protocardiinae Keen, 1951

Gênero Protocardia Beyrich, 1845

Subgênero Protocardia Beyrich, 1845

Protocardia (Protocardia) hillana (J. Sowerby, 1813)

(Figura 5: T)

1813 Cardium Hillanum - J. Sowerby, p. 41, est. 14.

2002 Protocardia hillana (Sowerby, 1813) - Abdelhamid \& EL QOT, p. 279, est. 6, fig. 1.

2006 Protocardia hillana (J. Sowerby, 1813) - El Qot, p. 78, est. 16, figs. 4-6.

2014 Protocardia hillana (J. Sowerby, 1813) - Ayoub-Hanna et al., p. 115, est. 10, figs. 8-9.

2014 Protocardia hillana (J. Sowerby) - Kumar, p. 509, fig. 3c.

2016 Protocardia hillana (Sowerby, 1813) - Benzaggagh, p. 201, figs. 16C1-C3, D1-D3, E1-E3, F1-F4, G1-G2, H1-H2, I1-I3.

2019 Protocardia (Protocardia) hillana - Ghenim et al., p. 29, figs. 6 D1-2, E1.

2019 Protocardia (Protocardia) hillana (J. Sowerby, 1813) - Ayoub-Hannaa et al., p. 176, est. IV, figs. K-N. (com lista de sinonímia).

Mate rial. Três exemplares preservados como molde interno (PG06-31-PG06-33).

Descrição. Valvas de tamanho médio, equilaterais, altura varia entre 41 a $49 \mathrm{~mm}$ e largura entre 37 a $51 \mathrm{~mm}$ (relação largura/altura média de 0,97). Contorno da concha subarredondado a oval. Margem anterior convexa. Margem posterior ligeiramente côncava. Umbo moderadamente curvado. A ornamentação não está preservada.

Discussão. El-Qot (2006) [26] e Ayoub-Hannaa et al. (2014) [23] descreveram Protocardia hillana em depósitos do Cretáceo Superior do Egito. Os exemplares exibem umbo, forma da concha e margens anterior e posterior semelhantes aos exemplares sergipanos. Por conta do desgaste, o material estudado não preserva a ornamentação da concha. Todavia, as características morfológicas compartilhadas entre os exemplares estudados e aqueles descritos para o Cretáceo Superior do Egito permitem associá-los à espécie $P$. hillana.

O material descrito é semelhante na morfologia da concha aos exemplares de P. hillana descritos e ilustrados para o Albiano do Marrocos [39] e Cenomaniano superior da Argélia [35]. Entretanto, os exemplares de Sergipe apresentam a concha ligeiramente mais arredondada quando comparado ao material do Marrocos. 
Ocorrência. Cretáceo Inferior da Inglaterra; Aptiano-Campaniano do Egito; Albiano de Angola e Marrocos; Cenomaniano do Líbano; Cenomaniano-Turoniano da Síria; Turoniano-Coniaciano da Áustria e Alemanha; Coniaciano-Santoniano do Sul da Índia, Cretáceo Superior do Nordeste dos Alpes e Líbia; "Senoniano" de Angola; Cenomaniano-Turoniano de Sergipe, Brasil [17, 35, 39].

\section{Subgênero Pachycardium Conrad, 1869 \\ Protocardia (Pachycardium) pauli (Coquand, 1862)}

(Figura 5: Q-R)

1862 Cardium Pauli H. Coq. - Coquand, p. 204, est. 10, figs. 5-6.

1933. Cardium (Protocardia) pauli Coq. - Riedel, p. 53, est. 10, fig. 3, est. 11, figs. 8-9.

1957 Protocardia (Protocardia) pauli (Coquand) - Dartevelle \& Freneix, p. 175, est. 30, figs. 4-6. v p 1999. Protocardia (Protocardia) pauli (Coquand, 1862) - Seeling, p. 125, est. 5, fig. 3 [est. 5, fig. $2=$ Granocardium $(G$.) tenuistriatum $]$.

2009 Protocardia (Pachycardium) pauli (Coquand, 1862) - Jaitly \& Mishra, p. 257, figs. 4L e M. 2011 Protocardia (Protocardia) pauli (Coquand, 1862) - Andrade \& Santos, p. 235, figs. 2.13 e 2.14 .

2016 Protocardia (Protocardia) pauli (Coquand, 1862) - Benzaggagh, p. 203, figs. 17A-E. 2019 Protocardia (Pachycardium) pauli (Coquand, 1862) - Ayoub-Hannaa et al., p. 177, figs. 1113, est. IV, figs. O-R, est. V, figs. A-E. (com lista de sinonímia).

Mate rial. 36 exemplares preservados como concha ou molde interno (PG06-17-PG06-30, PG0635, PG06-36, PG06-55, PG06-156, PG06-158, PG06-164, PG06-175, PG06-255-PG06-257, PG06-265，PG06-266，PG06-322，PG06-366，PG06-367，PG06-374，PG06-375，PG06-378PG06-380, PG06-399 e PG06-401).

Des crição. Valvas de tamanho pequeno a médio e com altura maior que largura (média da relação largura/altura igual a 0,82). A média da altura das valvas é $46,3 \mathrm{~mm}$ e da largura é $37,6 \mathrm{~mm}$ (Tabela 4). Valvas moderadamente infladas, convexas, subtriangulares a subarredondadas e inequilaterais. Margem posterior longa formando ângulo agudo com a margem ventral. Margem anterior convexa e unida a margem ventral em ângulo arredondado. Umbo estreito e proeminente. Ornamentação composta por linhas de crescimento comarginais.

Tabela 4: Medidas de exemplares selecionados de Protocardia (Pachycardium) pauli.

\begin{tabular}{cccc}
\hline Exemplar & L & A & L/A \\
\hline PG06-17 & $39^{*}$ & 55 & $0,71^{*}$ \\
PG06-18 & 44 & 46 & 0,95 \\
PG06-19 & 32 & 44 & 0,72 \\
PG06-20 & 25 & 35 & 0,71 \\
PG06-21 & 25 & 28 & 0,89 \\
PG06-22 & 27 & 37 & 0,73 \\
PG06-23 & 35 & 49 & 0,71 \\
PG06-24 & 39 & 53 & 0,73 \\
PG06-25 & 33 & 44 & 0,75 \\
PG06-26 & 37 & 51 & 0,72 \\
PG06-27 & 33 & 44 & 0,75 \\
PG06-28 & 37 & 48 & 0,77 \\
PG06-29 & 25 & 33 & 0,75 \\
PG06-35 & 36 & 43 & 0,84 \\
PG06-36 & 29 & 40 & 0,73
\end{tabular}




$\begin{array}{lccc}\text { PG06-55 } & 33^{*} & 46 & 0,72^{*} \\ \text { PG06-156 } & 36^{*} & 48 & 0,75^{*} \\ \text { PG06-158 } & 35 & 43 & 0,81 \\ \text { PG06-164 } & 34 & 36^{*} & 0,94^{*} \\ \text { PG06-175 } & 37 & 51 & 0,72 \\ \text { PG06-255 } & 36 & 47 & 0,77 \\ \text { PG06-256 } & 33 & 46 & 0,72 \\ \text { PG06-265 } & 41 & 51 & 0,80 \\ \text { PG06-266 } & 52 & 67 & 0,77 \\ \text { PG06-322 } & 40^{*} & 60 & 0,67^{*} \\ \text { PG06-366 } & 62 & 52 & 1,19 \\ \text { PG06-367 } & 49 & 57 & 0,86 \\ \text { PG06-374 } & 55 & 62 & 0,89 \\ \text { PG06-375 } & 49 & 59^{*} & 0,83^{*} \\ \text { PG06-378 } & 39 & 50 & 0,78 \\ \text { PG06-379 } & 39 & 52 & 0,75 \\ \text { PG06-380 } & 26 & 31 & 0,83 \\ \text { PG06-399 } & 54 & 30 & 1,80 \\ \text { PG06-401 } & 33 & 37^{*} & 0,89^{*}\end{array}$

Discussão. Protocardia (Pachycardium) pauli difere da Protocardia (Protocardia) hillana pelo formato subtriangular das valvas, maior convexidade, umbo mais estreito e menor relação largura e altura.

Segundo Ayoub-Hannaa et al. (2019) [17], P pauli apresenta uma grande variação no contorno da concha. No material aqui analisado, os exemplares (PG06-366 e PG06-399) também exibem essa variação no formato da concha, principalmente na relação largura e altura das valvas.

Os espécimes de Sergipe se assemelham na ornamentação, formato e convexidade da concha à $P$. pauli descrita e ilustrada para o Cretáceo de Camarões e Gabão [36]; para o intervalo Campaniano-Maastrichtiano da Índia [40]; para o Albiano do Marrocos [39].

Ocorrência. Cenomaniano da Argélia, Tunísia, Egito e Síria; Albiano do Marrocos; TuronianoCampaniano de Camarões, Gabão e Índia; Santoniano da Tunísia; Cenomaniano-Turoniano de Sergipe, Brasil [17, 39, 40].

\section{Protocardia sp.}

Mate rial. 13 exemplares preservados como molde interno (PG06-34, PG06-37, PG06-59, PG06159-PG06-161, PG06-174, PG06-178, PG06-227, PG06-268, PG06-272, PG06-277 e PG06371).

Descrição. Valvas moderadamente infladas, subarredondadas, equilaterais, com a largura menor que a altura (média da relação largura e altura igual a 0,72) e de tamanho pequeno a médio, com altura média de 43,8 mm e largura média de 30,9 mm (Tabela 5). Margem posterior maior que a anterior. Umbo estreito e proeminente. Ornamentação não preservada.

Tabela 5: Medidas dos exemplares selecionados de Protocardia sp.

\begin{tabular}{cccc}
\hline Exemplar & L & A & L/A \\
\hline PG06-34 & 37 & 57 & 0,65 \\
PG06-37 & 33 & 56 & 0,59 \\
PG06-159 & $41^{*}$ & 44 & $0,93^{*}$ \\
PG06-160 & 27 & 48 & 0,56 \\
PG06-161 & 21 & 27 & 0,78 \\
PG06-227 & 28 & $35^{*}$ & $0,80^{*}$
\end{tabular}




$\begin{array}{llll}\text { PG06-268 } & 31^{*} & 40^{*} & 0,78^{*} \\ \text { PG06-272 } & 29 * & 43^{*} & 0,67^{*}\end{array}$

Discussão. Os exemplares analisados são semelhantes à $P$. pauli no tamanho e na morfologia das valvas. Entretanto, devido ao estado de preservação, os exemplares foram deixados em nomenclatura aberta.

Ocorrência. Turoniano de Sergipe, Brasil (nesse estudo).

Superfamília Glossacea Gray, 1847

Família Dicerocardiidae Kutassy, 1934

Gênero Agelasina Riedel, 1932

Agelasina plenodonta Riedel, 1933

(Figura 5: U-V)

1933 Agelasina plenodonta n. gen. n. sp. Riedel, p. 58, est. 4, fig. 1, est. 12, figs. 1, 3-5.

1955 Agelasina plenodonta Riedel - Reyment, p. 142, est. IV, figs. 1a, b.

1957 Agelasina plenodonta Riedel - Dartevelle \& Freneix, p. 155, est. XXVI, fig. 3, est. XXVII, fig. $1 \mathrm{a}-\mathrm{c}, 2 \mathrm{a}-\mathrm{b}, 3$, est. XXVIII, fig. 1, 2.

2015 Agelasina plenodonta Riedel, 1932 - Moussavou, p. 316, figs. 4F, H, L, P.

2019 Agelasina plenodonta Riedel, 1933 - Ayoub-Hannaa et al., p. 173, est. III, figs. Q-T; est. IV, figs. A-D.

Material. Onze exemplares preservados como molde interno, alguns com restos de concha (PG06-38-PG06-44, PG06-165, PG06-267, PG06-358 e PG06-392).

Des crição. Valvas infladas, inequilaterais, de tamanho pequeno a médio, com a média da altura igual a 40,1 mm e largura a 39,7 $\mathrm{mm}$ (Tabela 6). Média da relação largura/altura igual a 1,00. O contorno das conchas varia entre subtrigonal a subtrapezoidal. Margens anterior e ventral arredondadas. Umbo grande e bastante recurvado. Ornamentação caracterizada por linhas de crescimento finas.

Tabela 6: Medidas dos exemplares selecionados de Agelasina plenodonta.

\begin{tabular}{cccc}
\hline Exemplar & L & A & L/A \\
\hline PG06-38 & 36 & 41 & 0,88 \\
PG06-39 & 48 & 35 & 1,37 \\
PG06-40 & 35 & 41 & 0,85 \\
PG06-41 & 36 & 38 & 0,94 \\
PG06-42 & 45 & 41 & 1,10 \\
PG06-44 & 21 & 23 & 0,91 \\
PG06-165 & 54 & 61 & 0,88 \\
PG06-267 & 51 & 45 & 1,13 \\
PG06-358 & 38 & 39 & 0,97 \\
PG06-392 & 33 & 37 & 0,89 \\
\hline
\end{tabular}

Discussão. O gênero Agelasina difere de Protocardia por conta do umbo curvado, maior convexidade da concha e da maior relação largura/altura.

Quando comparado aos exemplares de Agelasina plenodonta descritos para o Cretáceo Superior do Gabão e Camarões [36, 41], o material analisado assemelha-se na ornamentação e no formato da concha. Da mesma maneira, A. plenodonta ilustrada e descrita para o Coniaciano-Santoniano do Gabão, exibe convexidade da concha e formato do umbo similares aos exemplares aqui estudados [42]. 
Ocorrência. Coniaciano-Maastrichtiano de Camarões e Nigéria; Coniaciano-Santoniano do Gabão e Turoniano de Sergipe, Brasil [17, 36, 41, 42, 43].

\section{Agelasina sp.}

Mate rial. Quatro exemplares preservados como molde interno (PG06-45-PG06-47 e PG06-243). Des crição. Valvas subtrigonais, inequilaterais, infladas e de tamanho médio; altura varia entre 37 e $48 \mathrm{~mm}$ e largura entre 28 e $45 \mathrm{~mm}$ (Tabela 7). A média da relação largura e altura igual a 0,83. Margem anterior reta e posterior curvada. Umbo também curvado. Ornamentação marcada pela presença de linhas de crescimento.

Tabela 7: Medidas dos exemplares selecionados de Agelasina sp.

\begin{tabular}{cccc}
\hline Exemplar & L & A & L/A \\
\hline PG06-45 & 45 & $43^{*}$ & 1,05 \\
PG06-46 & 32 & 37 & 0,86 \\
PG06-243 & 28 & 48 & 0,58 \\
\hline
\end{tabular}

Discussão. Os exemplares analisados assemelham-se à A. plenodonta pelo tamanho, formato, ornamentação da concha. Entretanto, devido ao estado de preservação dos exemplares não foi possível chegar à identificação específica.

Ocorrência. Turoniano de Sergipe, Brasil (nesse estudo).

Gênero Ambocardia Beringer, 1949

Ambocardia planidorsata (Zittel, 1864)

(Figura 5: W)

1864 Isocardia planidorsata - Zittel, p. 36 [140], est. 5, fig. 4.

1987 Ambocardia planidorsata (Zittel, 1865) - Dhondt, p. 84, est. 5, figs. 6, 7.

2019 Ambocardia planidorsata (Zittel, 1864) - Ayoub-Hannaa et al., p. 174, fig. 10; est. IV, figs. E-F. (com lista de sinonímia).

Material. Dois exemplares preservados como molde interno (PG06-271 e PG06-383).

Des crição. Conchas inequilaterais, infladas e de tamanho médio, com a média de altura igual a $37,5 \mathrm{~mm}$ e largura a 38,5 mm. Média da relação largura/altura igual a 1,03. Margem anterior e ventral arredondadas. $\mathrm{O}$ contorno da concha subtrigonal. Umbo grande e moderadamente recurvado. Ornamentação não preservada.

Discussão. O gênero Ambocardia é bastante semelhante ao Agelasina no formato da concha subtrigonal, na convexidade das valvas e tamanho da concha. Entretanto, Ambocardia temoumbo menos recurvado e as margens anterior e posterior marcadas por estrutura em forma de crista. Os espécimes analisados se assemelham no contorno da concha à Ambocardia planidorsata descrita para o Cretáceo Superior da Áustria [29]. Essa espécie foi registrada recentemente na Formação Cotinguiba [17].

Ocorrência. "Senoniano" do nordeste dos Alpes; Santoniano-Maastrichtiano da Áustria; Campaniano da Alemanha; Turoniano de Sergipe, Brasil [17, 29].

Ordem Myoida Stoliczka, 1870

Superfamília Myoidea Lamarck, 1809

Familia Corbulidae Lamarck, 1818

Gênero Corbula Bruguière, 1797

Corbula sp. 
Material. Três exemplares incompletos de molde externo com resto da concha (PG06-214-PG06216).

Descrição. Valva subtrigonal e inflada. Umbo não preservado. Margem anterior curvada e posterior truncada. Ornamentação composta por costelas comarginais regularmente espaçadas.

Discussão. Os exemplares analisados assemelham-se à Corbula (Bicorbula) ushibukensis Tashiro \& Otsuka (1982), registrada para o Cretáceo Superior do Japão [44], no formato da concha e na ornamentação. Porém, devido ao estado de preservação do material, a identificação foi deixada em nomenclatura aberta.

Ocorrência. Turoniano de Sergipe, Brasil (nesse estudo). 


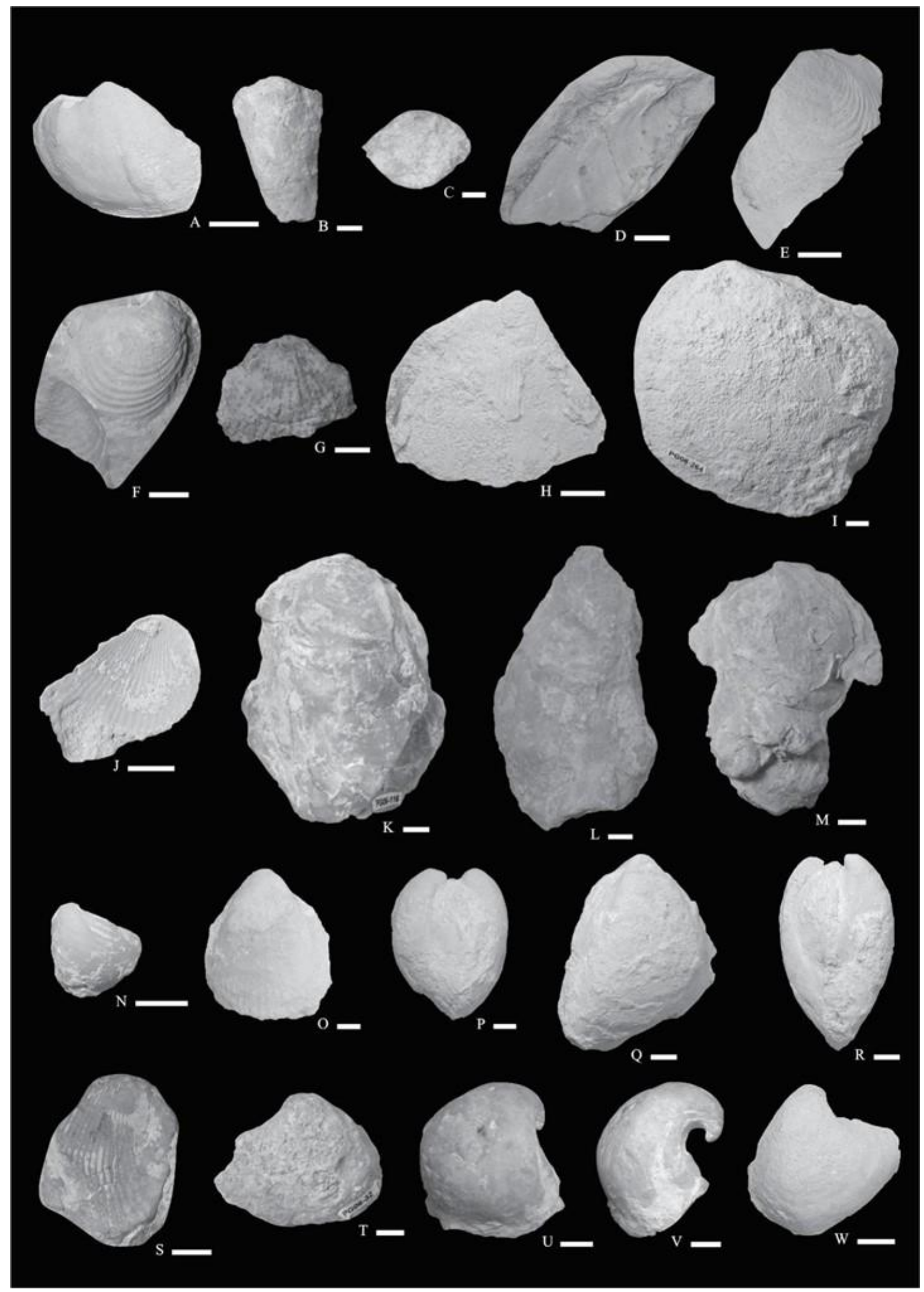

Figura 5: A. Molde interno da valva esquerda de Cucullaea (Idonearca) sp. (PG06-381), B-C Pinna sp.

(PG06-102). B. Vista lateral do molde interno; $\boldsymbol{C}$. vista (transversal) das valvas articuladas, $\boldsymbol{D}-\boldsymbol{E}$ Mytiloides subhercynicus (Petrascheck, 1903). D. Vista interna da valva esquerda incompleta (PG06173); E. molde interno da valva direita (PG06-166), F. Molde interno da valva esquerda de Mytiloides sp. (PG06-171), G. Valva esquerda da Plicatula sp. (PG06-140), H. Molde interno da valva Camptonectes sp. com resto de concha (PG06-16), I. Molde interno da valva esquerda de Plagiostoma 
sp. (PG06-264), J. Valva direita de Pseudolimea sp. (PG06-298), K-M Crassostrea sp. K. Vista externa de valva esquerda (PG06-116); L. Vista interna da valva direita (PG06-128); M. Vista externa da valva esquerda (PG06-74), N. Valva esquerda de Pycnodonte sp.(PG06-197), O-P Granocardium (Granocardium) productum (J. de C. Sowerby, 1832) (PG06-376). O. Molde interno da valva esquerda; P. Vista da margem anterior, $\boldsymbol{Q}-\boldsymbol{R}$ Protocardia pauli (Coquand, 1862) (PG06-298). Q. Molde interno da valva direita; $\boldsymbol{R}$. Vista da margem anterior, $S$. Valva direita de Granocardium sp. (PG06-254), T. Molde interno da valva direita da Protocardia hillana (J. Sowerby, 1813) (PG06-32), U-V Agelasina plenodonta

Riedel, 1932 (PG06-40). U. Molde interno da valva esquerda; V. Vista da área umbonal da valva esquerda, W. Molde interno da valva esquerda de Ambocardia planidorsata (Zittel, 1865) (PG06-383). Escalas iguais a $10 \mathrm{~mm}$. Fonte: Os autores.

Subclasse Autobranchia Grobben, 1894

Ordem Pholadomyida Newell, 1965

[= ANOMALODESMATA Dall, 1889]

Superfamília Pholadomyoidea King, 1844

Família Pholadomyidae King, 1844

Gênero Pholadomya G.B. Sowerby, 1823

Pholadomya (Pholadomya) cf. nodulifera Münster, 1841

(Figura 6: A)

cf. 1841 Pholadomya nodulifera - Münster in Goldfuss, p. 273, est. 158, figs. 2a-b.

cf. 1987 Pholadomya nodulifera Münster - Dhondt, p. 89, est. 5, figs. 4-5.

cf. 2015 Pholadomya (Pholadomya) nodulifera Münster, 1841 - Ayoub-Hannaa et al.,p. 39, figs. 5H-J, 7A-G. (com lista de sinonímia).

Material. Um exemplar articulado preservado como molde interno (PG06-359).

Descrição. Valva grande, inequilateral, inflada, alongada e ligeiramente oval. A altura igual a 64 $\mathrm{mm}$ e largura a $100 \mathrm{~mm}$. Margens anterior e posterior convexas ligada à margem ventral em ângulo arredondado. O umbo amplo e convexo. Ornamentação caracterizada por costelas radiais bem desenvolvidas cruzadas por costelas comarginais, que produz um padrão reticulado.

Discussão. O molde analisado apresenta as valvas parcialmente deslocadas e com a valva direita mais desgastada. Pholadomya (Pholadomya) cf. nodulifera se assemelha na ornamentação e no formato da concha à Pholadomya (Pholadomya) nodulifera descrita para o Turoniano de Sergipe [16]. Entretanto, devido ao exemplar analisado apresentar as margens anterior e ventral fragmentadas, além da ornamentação parcialmente desgastada, não foi possível definir o número de costelas radiais.

Ocorrência. Cenomaniano do Egito e Ásia Central; Turoniano de Sergipe (Brasil); TuronianoConiaciano da Alemanha, nordeste dos Alpes e República Checa; Santoniano superior da Áustria e Maastrichtiano da Polônia [16].

Gênero Homomya Agassiz, 1843

Homomya bisinuosa (White, 1887)

(Figura 6: B)

1887 Myacites bisinuosus sp. nov. - White, p. 104, est. 7, figs. 6-7.

1937 Homomya bisinuosa (White) - Maury, p. 79, est. 10, figs. 15-16.

2015 Homomya bisinuosa (White, 1887) - Ayoub-Hannaa et al., p. 49, figs. 10A-C. (com lista de sinonímia). 
Mate rial. Um exemplar preservado como molde interno (PG06-269).

Descrição. Concha de tamanho médio, moderadamente inflada, inequilateral, alongada a oval. Altura igual a $30 \mathrm{~mm}$ e largura a $51 \mathrm{~mm}$. As margens posterior e anterior arredondadas, unidas com a margem ventral em ângulo obtuso. Margem ântero-dorsal curta e ligeiramente côncava, ligada com a margem anterior em ângulo quase reto. Margem póstero-dorsal levemente côncava. Umbo ligeiramente proeminente. Ornamentação composta de linhas comarginais.

Discussão. $O$ espécime descrito se assemelha no formato e na ornamentação da concha à Homomya bisinuosa descrita para o Cenomaniano-Turoniano de Sergipe [16].

Ocorrência. Albiano e Cenomaniano-Turoniano de Sergipe (Brasil); Turoniano da Península do Sinai, Egito [16].

Homomya cf. brasiliensis (White, 1887)

(Figura 6: C)

cf. 1887 Glycimeris brasiliensis sp. nov. White, p. 111, est. 7, figs. 1-2.

cf. 1937 Panopea brasiliensis (White) - Maury, p. 81, est. 11, figs. 11-12.

cf. 2015 Homomya brasiliensis (White, 1887) - Ayoub-Hannaa et al., p. 50, figs. 10D-H. (com lista de sinonímia).

Mate rial. Um exemplar preservado como molde interno (PG06-320).

Descrição. Concha de tamanho médio, subretangular a subquadrada, inequilateral e moderadamente inflada, com altura equivalente a $36 \mathrm{~mm}$ e largura a $42 \mathrm{~mm}$. Margem anterior curta e quase reta. Margem posterior fragmentada, unida com a margem ventral em ângulo arredondado. Margem ventral ligeiramente arredondada. Margem ântero-dorsal curta e ligada a margem ventral em ângulo reto. Umbo pouco proeminente e arredondado. Ornamentação não preservada.

Discussão. O exemplar analisado é incompleto, porém assemelha-se na morfologia da concha à Homomya brasiliensis descrita para o Cenomaniano-Turoniano de Sergipe [16]. Entretanto, devido a margem posterior fragmentada e ornamentação desgastada, foi deixado em nomenclatura aberta.

Ocorrência. Albiano e Cenomaniano-Turoniano de Sergipe (Brasil) [16].

Família Pleuromyidae Zittel, 1895

Gênero Pleuromya Agassiz, 1842

Pleuromya ligeriensis (d'Orbigny, 1845)

(Figura 6: D)

1845 Pholadomya ligeriensis d'Orbigny, 1844 [sic] - d'Orbigny, p. 355, est. 363, figs. 8-9.

1912 Liopistha (Psilomya) cf. L. ligeriensis (d'Orbigny) - Pervinquière, p. 292, est. 20, fig. 22.

2014 Pleuromya ligeriensis (d'Orbigny 1845) - Ayoub-Hannaa et al., p. 128, est. 13, fig. 1.

2015 Pleuromya ligeriensis (d'Orbigny, 1845) - Ayoub-Hannaa et al., p. 50, figs. 10I, J. (com lista de sinonímia).

Mate rial. Um exemplar articulado preservado como molde interno (PG06-14).

Des crição. Concha de tamanho médio, moderadamente inflada, contorno oval. A largura da valva é igual a $53 \mathrm{~mm}$ e altura a $46 \mathrm{~mm}$. Margem anterior curta e truncada. Margem posterior arredondada e alongada. Umbo proeminente e um pouco curvado. Ornamentação bastante desgastada, porém, pode-se observar algumas linhas de crescimento comarginais.

Discussão. O exemplar analisado é semelhante no formato e convexidade da concha à Pleuromya ligeriensis descrita e ilustrada para o Cenomaniano-Turoniano de Sergipe [16]. Também o 
exemplar da Formação Cotinguiba se assemelha no contorno da margem anterior e do umbo à Pleuromya congoensis descrita para o Turoniano do Gabão [36], porém, P. congoensis difere pela presença de linhas de crescimento mais espessas e concha mais alongada na margem posterior.

Ocorrência. Cenomaniano da Tunísia; Cenomaniano-Turoniano da Argélia; Cenomaniano do Egito; Cenomaniano-Turoniano de Sergipe, Brasil; Turoniano da França e Nigéria [16].

\section{Pleuromya cf. servesensis Choffat, 1901}

(Figura 6: E)

cf. 1902 Pleuromya servesensis - Choffat,p. 132, est. 9, figs. 1-3.

cf. 2015 Pleuromya servesensis Choffat, 1902 - Ayoub-Hannaa et al., p. 52, figs. 11A-E. (com lista de sinonímia).

Mate rial. Dois exemplares preservados como molde interno (PG06-124 e PG06-323).

Descrição. Valvas de tamanho médio, levemente infladas e alongadas. A média da largura igual a 46,5 $\mathrm{mm}$ e média altura a $30 \mathrm{~mm}$. Margem posterior arredondada e a anterior curta. Margem póstero-dorsal reta a ligeiramente côncava. Área umbonal ampla e inflada com o bico pouco proeminente. Ornamentação composta por linhas de crescimento comarginais irregulares separadas por amplos espaços.

Discussão. Os exemplares analisados são semelhantes na convexidade e no formato da concha à Pleuromya servesensis ilustrada e descrita para o Cretáceo Superior da Formação Cotinguiba [16]. Porém, devido ao estado de preservação da margem anterior fragmentada e da ornamentação desgastada, foi deixado em nomenclatura aberta.

Ocorrência. Albiano do Texas, EUA; Albiano-Coniaciano da Nigéria; Cenomaniano-Turoniano de Sergipe, Brasil e Turoniano de Portugal [16].

Superfamilia Poromyoidea Dall, 1886

Familia Poromyidae Dall, 1886

Gênero Liopistha Meek, 1864

Subgênero Sergipemya Ayoub-Hannaa et al., 2015

Liopistha (Sergipemya) alta (Roemer, 1852)

(Figura 6: F-H)

1852 Homomya alta n. sp. - Roemer, p. 45, est. 6, fig. 11.

1912 Liopistha (Psilomya) alta Roemer - Pervinquière, p. 293, est. 20, fig. 20.

pars. 2011 Liopistha (Psilomya) ligeriensis (d'Orbigny, 1945) - Andrade \& Santos, p. 191, figs. 2.3 e 2.4 .

2015 Liopistha (Sergipemya) alta (Roemer, 1852) - Ayoub-Hannaa et al., p. 58, figs. 12I-M, 13AD. (com lista de sinonímia).

2018 Liopistha (Sergipemya) alta (Roemer, 1852) - Scott \& Claggett, p.8, figs. 11.5-11.8.

Mate rial. Nove exemplares preservados como molde interno, alguns deles com restos da concha e articulados (PG06-08-PG06-12, PG06-109, PG06-360, PG06-362 e PG06-364).

Des crição. Concha subtrigonal e bastante inflada (média $\mathrm{C} / \mathrm{L}$ igual 0,74 ). A média da altura igual a 69,8 mm e média da largura igual a 78,4 mm (Tabela 8). A média da relação largura/altura igual a 1,11. Margem anterior truncada que forma uma depressão com o umbo. Margem ventral ampla e convexa. Margem ântero-dorsal moderadamente convexa e margem póstero-dorsal ligeiramente côncava. Umbo grande e proeminente. Ornamentação composta de linhas de crescimento comarginais. 
Discussão. Os exemplares analisados se assemelham no contorno e convexidade da concha à Liopistha (Sergipemya) alta (Roemer, 1852) para o Cretáceo Superior de Sergipe [16]. O material da Bacia de Sergipe-Alagoas também é similar ao descrito e ilustrado para o intervalo AlbianoCenomaniano inferior do Texas (Estados Unidos) [45]. O material ilustrado por Andrade \& Santos [13] para Formação Cotinguiba como Liopistha (Psilomya) ligeriensis foi revisado e devido ao contorno e tamanho da concha foi reposicionado na espécie aqui estudada.

Ocorrência. Cenomaniano do Texas, Egito e Tunísia; Cenomaniano-Turoniano de Sergipe, Brasil [16].

Tabela 8: Medidas dos exemplares de Liopistha (Sergipemya) alta.

\begin{tabular}{cccccc}
\hline Exemplar & L & A & C & L/A & C/L \\
\hline PG06-08 & $80^{*}$ & 74 & $48^{*}$ & $1,08^{*}$ & $0,60^{*}$ \\
PG06-10 & 82 & 76 & 65 & 1,08 & 0,79 \\
PG06-11 & 81 & 74 & 67 & 1,09 & 0,82 \\
PG06-12 & $40^{*}$ & 45 & - & $0,89^{*}$ & - \\
PG06-109 & 87 & 65 & - & 1,34 & - \\
PG06-360 & $95^{*}$ & 86 & 60 & $1,10^{*}$ & $0,63^{*}$ \\
PG06-362 & 84 & 69 & 58 & 1,21 & 0,69 \\
\hline
\end{tabular}

Gênero Megaporomya Ayoub-Hannaa et al, 2013

Megaporomya reymenti Ayoub-Hannaa et al., 2013

(Figura 6: I-J)

v1983 Liopistha (Psilomya) supermensa White [sic]. Bengtson, p. 47.

pars. 2011 Liopistha (Psilomya) supermensa (White, 1887) - Andrade \& Santos, p. 234, figs. 2.52.7 .

2013 Megaporomya reymenti gen. et sp. nov. Ayoub-Hannaa et al. p. 200, figs. 4-6, 9. (com lista de sinonímia).

Material. Treze exemplares preservados como molde interno, por vezes com restos da concha e articulados (PG06-01-PG06-07, PG06-107, PG06-108, PG06-336, PG06-361, PG06-363 e PG06-365).

Descrição. Concha alongada, arredondada e bastante inflada (média C/L 0,66). A largura varia entre 76 e $110 \mathrm{~mm}$, altura entre 54 e $83 \mathrm{~mm}$ (Tabela 9). A média da relação largura/altura igual a 1,33. Margens anterior e posterior ligeiramente convexas. Umbo grande e proeminente. Ornamentação caracterizada pela presença de costelas comarginais separadas por amplos espaços cortadas por linhas radiais de pequenos tubérculos.

Discussão. Os exemplares analisados apresentam características do formato da concha e da ornamentação semelhantes à Megaporomya reymenti descrita para o Cretáceo Superior de Sergipe [14]. O material descrito também se assemelha com os exemplares de Megaporomya? cf. supermensa (WHITE, 1887) registrados para o Cretáceo Superior de Sergipe [16], por causa da concha inflada e arredondada. Entretanto, $M$. reymenti tem a margem posterior mais larga e ornamentação caraterizada por costelas comarginais cruzadas por linhas radiais de tubérculos. Os dois exemplares ilustrados como Liopistha (Psilomya) supermensa para Formação Cotinguiba [13] foram revisados e reposicionados para M. reymenti pela semelhança no formato e tamanho da concha. 


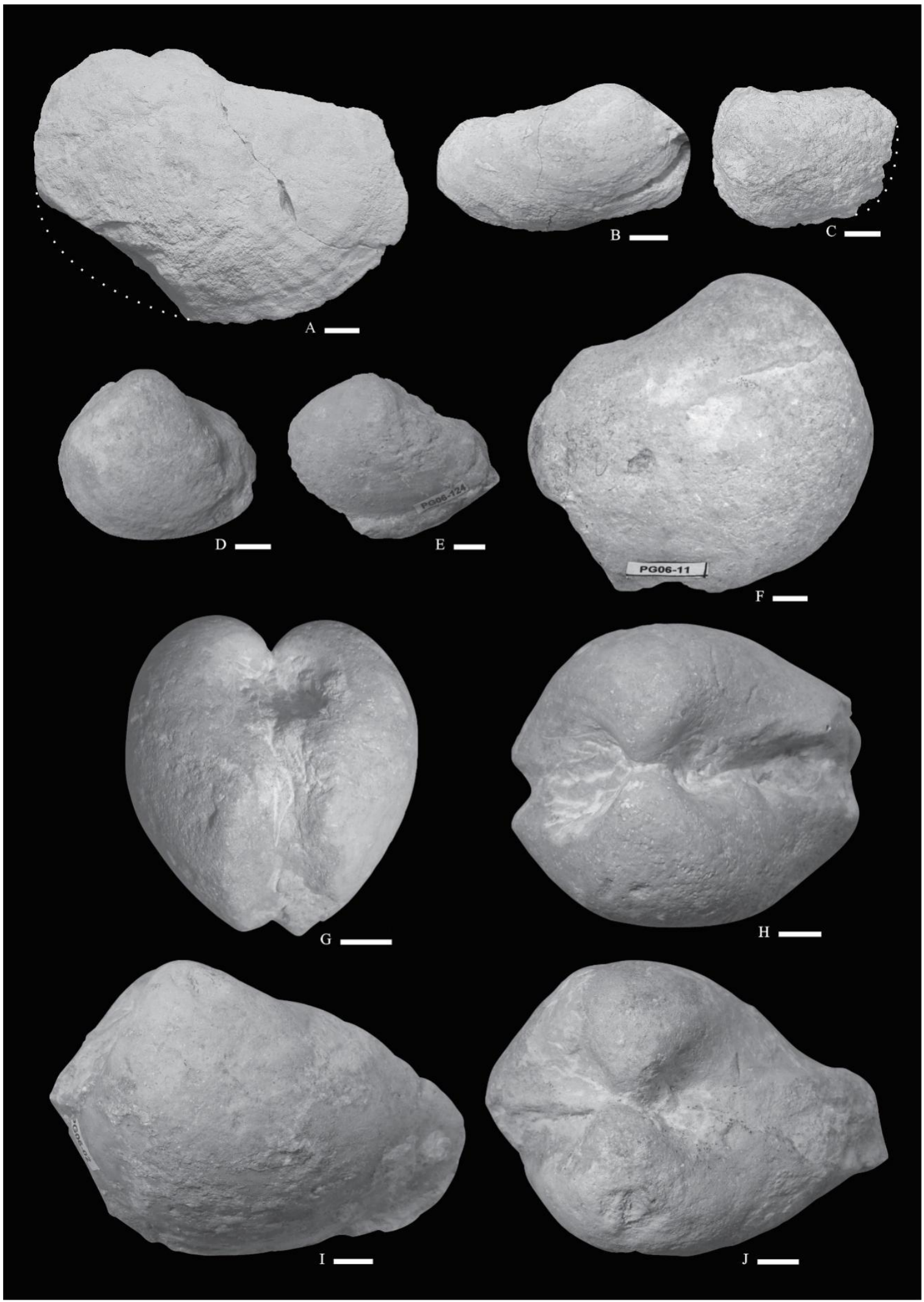

Figura 6: A. Molde interno da valva esquerda de Pholadomya (Pholadomya) cf. nodulifera Münster, 1841 (PG06-359) com umbo da valva direita deslocado, B. Molde interno da valva direita de Homomya bisinuosa (White, 1887) (PG06-269), C. Molde interno da valva esquerda de Homomya cf. brasiliensis (White, 1887) (PG06-320), D. Molde interno da valva esquerda de Pleuromya ligeriensis (D'Orbigny, 1845) (PG06-14), E. Molde interno da valva esquerda de Pleuromya cf. servesensis Choffat, 1901 (PG06124), F-H Liopistha (Sergipemya) alta (Roemer, 1852) (PG06-11). F. Molde interno da valva direita; G. 
Vista da margem anterior; H. Vista da margem dorsal, I-J Megaporomya reymenti (PG06-02). I. Vista da valva direita; J. Vista da margem dorsal. Escalas iguais a $10 \mathrm{~mm}$. Fonte: Os autores.

Ocorrência. Turoniano de Sergipe, Brasil [14].

Tabela 9: Medidas dos exemplares selecionados de Megaporomya reymenti.

\begin{tabular}{cccccc}
\hline Exemplar & L & A & C & L/A & C/L \\
\hline PG06-01 & 108 & 81 & 69 & 1,33 & 0.64 \\
PG06-02 & 110 & 75 & 66 & 1,47 & 0,60 \\
PG06-03 & 98 (VE) & 77 & 68 & 1,27 & 0,69 \\
PG06-05 & 99 & 74 & - & 1,34 & - \\
PG06-06 & 94 & $63^{*}$ & $66^{*}$ & $1,49^{*}$ & $0,70^{*}$ \\
PG06-07 & 96 & $65^{*}$ & $65^{*}$ & $1,47^{*}$ & $0,68^{*}$ \\
PG06-107 & $88^{*}$ & 77 & - & $1,14^{*}$ & - \\
PG06-108 & $76^{*}$ & 54 & - & $1,40^{*}$ & - \\
PG06-336 & 89 & 67 & - & 1,33 & - \\
PG06-361 & $105^{*}$ & 83 & 66 & $1.27^{*}$ & $0,63^{*}$ \\
PG06-363 & $79^{*}$ & 65 & 60 & $1,22^{*}$ & $0,76^{*}$ \\
PG06-365 & 88 & 73 & - & 1,21 & - \\
\hline
\end{tabular}

\section{CONCLUSÃO}

Neste trabalho foram descritos os moluscos da classe Bivalvia da localidade Pedro Gonçalves 6 (Turoniano médio), Formação Cotinguiba, Bacia de Sergipe-Alagoas. A análise taxonômica permitiu identificar 27 táxons (19 gêneros) distribuídos em 14 famílias: Cucullaeidae, Pinnidae, Inoceramidae, Plicatulidae, Pectinidae, Pectinidae, Ostreidae, Gryphaeidae, Cardiidae, Dicerocardiidae, Corbulidae, Pholadomyidae, Pleuromyidae e Poromyidae.

\section{AGRADECIMENTOS}

À Coordenação de Pesquisa da Universidade Federal de Sergipe (COPES-UFS) pela bolsa de Iniciação Científica concedida a E. Franco Neto e M. N. Santana, assim como aos revisores deste trabalho pelas correções relevantes e construtivas. Este trabalho apresenta parte dos resultados do Trabalho de Conclusão de Curso do primeiro autor.

\section{REFERÊNCIAS BIBLIOGRÁFICAS}

1. Bengtson P. The Cenomanian-Coniacian of the Sergipe Basin, Brazil. Fossils and Strata. 1983 Jan;12:1 78.

2. Seeling J, Bengtson P. Palaeobiogeography of the upper Cenomanian-lower Turonian macroinvertebrates of the Sergipe Basin, norteastern Brazil. In: Wagreich M, editor. Aspects of the Cretaceous Stratigraphy and Palaeobiogeography. Schriftenreihe der Erdwissenschaftlichen Kommissionen der Österreichen Akademie der Wissenschaften. 2002 Jan;15:151-168.

3. White CA. Contribuições á Paleontologia do Brasil. Arch Museu Nac Rio de Janeiro. 1887;7:1-273.

4. Maury CJ. O Cretáceo de Sergipe. Serviço Geológico e Mineralógico do Brasil, Monographia XI. 1937; 11:1-283.

5. Hessel MHR. Alguns inoceramídeos (Bivalvia) radialmente ondulados do Turoniano inferior de Sergipe. In: 8. Congresso Brasileiro de Paleontologia, Rio de Janeiro, 1983. Departamento Nacional da Produção Mineral, Série Geologia. 1986;27:227-237.

6. Hessel MHR. Lower Turonian inoceramids from Sergipe, Brazil: systematics, stratigraphy and palaeoecology. Fossils and Strata. 1988;22:1-49. 
7. Seeling J. Palaeontology and biostratigraphy of the macroinvertebrate fauna of the Cenomanian-Turonian transition of the Sergipe Basin, northeastern Brazil, with systematic descriptions of bivalves and echinoids [tese]. Heidelberg: Universidade de Heidelberg, 1999. 185p.

8. Seeling J, Bengtson P. Cenomanian oysters from the Sergipe Basin, Brazil. Cretac Res. 1999 Dez;20: 747-765, doi:10.1006/cres.1999.0190.

9. Seeling J, Bengtson P. The bivalve Pinna cretacea (Schlotheim, 1813) from the Cretaceous of Brazil. Acta Palaeontol Pol. 2003 Set;48(3):475-480.

10. Seeling J, Bengtson P. The Late Cretaceous bivalve Didymotis Gerhardt, 1897 from Sergipe, Brazil. Paläontol Z. 2003 Abr;77(1):153-160, doi:10.1007/bf03004565.

11. Andrade EJ, Seeling J, Bengtson P, Souza-Lima W. The bivalve Neithea from the Cretaceous of Brazil. J South Am Earth Sci. 2004 Set;17(1):25-38, doi:10.1016/j.jsames.2004.05.006.

12. Andrade EJ. Turonian inoceramids and biostratigraphy of the Sergipe Basin, northeastern Brazil: an integrated study of the Votorantim and Nassau quarries [tese]. Heidelberg: Universidade de Heidelberg, 2005. $155 \mathrm{p}$.

13. Andrade EJ, Santos MT. Moluscos biválvios do Turoniano (Cretáceo Superior) da bacia de Sergipe. In: Carvalho IS, Srivastava JrNK, Strohschoen O, Lana CC, editores. Paleontologia: Cenários de Vida. Rio de Janeiro: Interciência; 2011;4. p. 229-238.

14. Ayoub-Hannaa WS, Bengtson P, Fürsich FT, Andrade EJ. Megaporomya reymenti gen. et sp. nov. (Bivalvia, Pholadomyida) from the upper Turonian (Upper Cretaceous) of the Sergipe Basin, northeastern Brazil. Rev Bras Paleontol. 2013 Ago;16(2):197-212, doi:10.4072/rbp.2013.2.03.

15. Bengtson P, Ayoub-Hannaa WS, Fürsich FT, Heinze M. Taxonomy and palaeoecology of Pinna (P.) cretacea (Schlotheim, 1813) from the Upper Cretaceous of the Sergipe Basin, Brazil. Rev Bras Paleontol. 2014 Set/Dez;17(3):289-306, doi:10.4072/rbp.2014.3.02.

16. Ayoub-Hannaa WS, Bengts on P, Fürsich FT, Andrade EJ. Cenomanian-Coniacian (Upper Cretaceous) bivalves of the Sergipe Basin, Brazil: Order Pholadomyida. Rev Bras Paleontol. 2015 Jan/Apr; 18(1):31 70, doi:10.4072/rbp.2015.1.03.

17. Ayoub-Hannaa WS, Bengtson P, Fürsich FT, Andrade EJ. Cenomanian-Turonian (Cretaceous) heterodont bivalves from the Sergipe Basin, Brazil. Rev Paléobiol. 2019 Jun; 38 (1):151-228, doi:10.5281/zenodo.3265243.

18. Souza-Lima W, Andrade EJ, Bengtson P, Galm PC. A Bacia de Sergipe-Alagoas: Evolução geológica, estratigráfica e conteúdo fóssil/The Sergipe-Alagoas Basin: Geological evolution, stratigraphy and fossil content. Fundação Paleontológica Phoenix. 2002 Jan; Edição especial 1:1-31.

19. Campos Neto OPA, Souza Lima W, Cruz FEG. Bacia de Sergipe Alagoas. Bol Geoci Petrobrás. 2007 May/Nov.; 15(2):405-415.

20. Koutsoukos EAM, Destro N, Azambuja Filho NC, Spadini AR. Upper Aptian-Lower Coniacian Carbonate Sequences in the Sergipe Basin, Northeastern Brazil. Cretaceous Carbonate Platforms. 1993; 56(11):127-144.

21. Feijó FJ. Bacias de Sergipe e Alagoas. Bol Geoci Petrobras. 1994 Jan/Mar; 8(1):149-161.

22. Cox LR et al. In: Moore RC, editor. Treatise on Invertebrate Paleontology: Part N. The Geological Society of America and The University of Kansas. 1969;1-2(Mollusca 6 Bivalvia):1-952.

23. Ayoub-Hannaa WS, Fürsich FT, El Qot GM. Cenomanian-Turonian bivalves from eastern Sinai, Egypt. Palaeontogr Abt A. 2014 Fev;301(3-6):63-168, doi: 10.1127/pala/301/2014/63.

24. Walaszczyk I, Cobban WA. Taxonomy of the lower and lower middle Turonian inoceramids from Pueblo. In: Kennedy WJ, Walaszczyk I, Cobban WA, editores. Pueblo, Colorado, USA, candidate Global boundary Stratotype Section and Point for the base of the Turonian Stage of the Cretaceous, and for the base of the Middle Turonian Substage, with a revision of the Inoceramidae (Bivalvia). Acta Geologica Polonica. 2000; 50:295-334.

25. El-Hedeny M, Abdel Aal AA, Maree M, Seeling J. Plicatulid bivalves from the Coniacian-Santonian Matulla Formation, Wadi Sudr, western Sinai, Egypt. Cretaceous Res. 2001 Jun;22(3):295-308, doi:10.1006/cres.2001.0257.

26. El-Qot GM. Late Cretaceous macrofossils from Sinai, Egypt. Beringeria. 2006 Oct;36:1-163.

27. Kirkland JI. Paleontology of the Greenhorn Cyclothem (Cretaceous: late Cenomanian to middle Turonian) at Black Mesa, northeastern Arizona. Bull New Mexico Mus Nat Hist Sci. 1996;9:1-131.

28. Sørensen AM, Surlyk F, Jagt JWM. Adaptive morphologies and guild structure in a high-diversity bivalve fauna from an early Campanian rocky shore, Ivö Klack (Sweden). Cretaceous Res. 2012 Feb;33(1):2141, doi:10.1016/j.cretres.2011.07.004. 
29. Dhondt AV. Bivalves from the Hochmoos Formation (Gosau-Group, Oberösterreich, Austria). Annalen des Naturhistorischen Museums in Wien, Serie A. 1987 Apr;88:41-101.

30. Dhondt AV. Late Cretaceous Limea (Pseudolimea) species of Europe. Bulletin de Linstitut Royal des Sciences Naturelles de Belgique. 1989;59:105-125.

31. Ayoub-Hannaa WSA. Taxonomy and palaeoecology of the Cenomanian-Turonian macro-invertebrates from eastern Sinai, Egypt [tese]. Würzburg: Universidade de Würzburg, 2011. 410 p.

32. Pugaczewska H. The Upper Cretaceous Ostreidae from the Middle Vistula region (Poland). Acta Palaeontol Pol. 1977;22(2):187-204.

33. Musavu Moussavou B. Systematics, palaeoecology and taphonomy of Turonian oysters from the northem Gabon Coastal Basin. Geodiversitas. 2017 Jun;39(2):213-224, doi: 10.5252/g2017n2a3.

34. Aouissi R, Salmi-Laouar S, Ferré B. Macro-invertébrés du Cénomanien du Djebel Metrassi(Batna, NE Algérie): Systématique et biostratigraphie. Estud Geol. 2018 Nov;74(2):1-39, doi:10.3989/egeol.43158.492.

35. Ghenim AF, Benyoucef M, El-Qot G, Adaci M, Bensalah M. Upper Cenomanian bivalves from the Guir Basin (southwestern Algeria): Order Veneroida. Ann Paléontol. 2019 Jan;105(1):21-38, doi:10.1016/j.annpal.2018.10.004.

36. Dartevelle E, Freneix S. Mollusques fossiles du Crétacé de la côte occidentale d'Afrique du Cameroun à l’Angola. II. Lamellibranches. Ann Musée Royal du Congo Belge. 1957;20:1-271.

37. Abdelhamid MAM, El-Qot GM. Somer Upper Cretaceous Bivalves from Gabal El-Minsherah and Gabal El-Hamra, North and West Central Sinai Egypt. Egypt J Paleontol. 2002;2:259-288.

38. Musavu Moussavou B, Ndong Ondo SM, Voubou MM. Turonian bivalves from the coastal basin of Gabon, south of Libreville. Bulletin de l'Institut Scientifique,Rabat, Section Sciences de la Terre. 2013 Jan;35:1-8.

39. Benzaggagh M. Bivalves crétacés de la Formation des Marnes et calcaires lumachelles à huîtres (Albien supérieur-Cénomanien inférieur) des Rides sud-rifaines (région de Moulay Idriss Zerhoun, nord Maroc). Ann Paléontol. 2016 Jul-Sept;102(3):183-211, doi:10.1016/j.annpal.2016.08.003.

40. Jaitly AK, Mishra SK. Campanian-Maastricthian (Late Cretaceous) veneroids (Bivalvia: Heterodonta) from the Ariyalur Group, South India. Palaeoworld. 2009 Sept;18(4):251-262, doi:10.1016/j.palwor.2009.09.001.

41. Reyment RA. Upper Cretaceous Mollusca (Lamellibranchia and Gastropoda) from Nigeria. Colonial Geol Mineral Resour. 1955;5(2):127-155.

42. Moussavou BM. Bivalves (Mollusca) from the Coniacian-Santonian Anguille Formation from Cap Esterias, northern Gabon, with notes on paleoecology and paleobiogeography. Geodiversitas. 2015 Sept;37(3):315-324, doi:10.5252/g2015n 3a2.

43. Riedel L. Die Oberkreide vom Mungofluß in Kamerun und ihre Fauna. Beiträge zur geologischen Erforschung der deutschen Schutzgebiete. 1933;16:1-154.

44. Kozai T. A study of Corbula and Nipponicorbula (Bivalvia) from the Cretaceous of Japan. Trans Proc Paleontol Soc Japan. 1989 Apr; 1989(153):36-47, doi:10.14825/prpsj1951.1989.153_36.

45. Scott RW, Claggett BW. Albian infaunal Pholadomyida (Cretaceous Bivalvia), Comanchean Carbonate Shelf, Texas. J Paleontol. 2018 Apr;92(4):1-23, doi:10.1017/jpa.2017.139. 